\title{
Laboratory Model Tests on Flow Erosion Failure Mechanism of a Slope Consisting of Anqing Group Clay Gravel Layer
}

\author{
Kang Huang, ${ }^{1,2}$ Haipeng Duan, ${ }^{3}$ Yuelin Yi, ${ }^{3}$ Fei Yu $\mathbb{D}^{1},{ }^{1}$ Shanxiong Chen, ${ }^{1}$ \\ and Zhangjun Dai $\mathbb{B}^{1}$ \\ ${ }^{1}$ State Key Laboratory of Geomechanics and Geotechnical Engineering, Institute of Rock and Soil Mechanics, Chinese Academy \\ of Sciences, Wuhan 430071, China \\ ${ }^{2}$ University of Chinese Academy of Sciences, Beijing 100049, China \\ ${ }^{3}$ Anhui Transportation Holding Group Co., Ltd, Hefei 230000, China
}

Correspondence should be addressed to Zhangjun Dai; zjdai@whrsm.ac.cn

Received 24 January 2021; Revised 13 February 2021; Accepted 1 March 2021; Published 15 March 2021

Academic Editor: Yu Wang

Copyright (C) 2021 Kang Huang et al. This is an open access article distributed under the Creative Commons Attribution License, which permits unrestricted use, distribution, and reproduction in any medium, provided the original work is properly cited.

The Anqing group clay gravel layer is a special geological body composed of gravel and clay. In excavation projects, involving this soil, such a gravel layer, is prone to slope collapse and instability under the influence of rainfall. To clearly understand the failure mechanism and influencing factors of clay gravel slopes, an indoor artificial rainfall erosion model testing was carried out to analyse the effect of various slope ratios, gravel contents, and rainfall intensities. The slope erosion damage form, runoff rate, infiltration rate, scoured material, and slope stability of the clay gravel slope were studied. The test results show that sloping surfaces of the gentle slope were mainly damaged by erosion, and the degree of damage gradually increased from the top to the bottom of the sloping surface; however, the stability of the surface was good. In the case of the sloping surface layer of the steep slope, large-scale landslides occurred, and the stability of the surface was poor. When the gravel content was small, the surface failure was manifested as a gully failure. When the gravel content was large, it was manifested as a "layer-by-layer sliding" failure. The degree of influence of different conditions on the stable runoff rate was as follows: rainfall intensity>slope ratio>gravel content. The degree of influence of the parameters on the stable infiltration rate was as follows: slope ratio>rainfall intensity>gravel content. On gentle slopes, the total mass of the scoured material was inversely proportional to the gravel content and directly proportional to the rainfall intensity; on a steep slope, the total mass of the scoured material increased with an increase in the rainfall intensity and gravel content. Moreover, the slope ratio was the key influencing factor to decide whether there was gravel in the scoured material.

\section{Introduction}

The clay gravel layer of the Anqing group is widely distributed in the Anqing section in the upper reaches of the Wanjiang River. It is composed of clayey gravel alluvial strata from the Neogene to the quaternary early Pleistocene. It is a special engineering geological body comprising gravel as an aggregate and clay as a filling component and can be characterized as a typical fluvial alluvial earth-rock mixture.

Earlier researchers have predominantly investigated soil erosion of loess and collapsed hills; however, there have been very few studies on the special clay gravel layers of the Anqing group. Currently, research on soil erosion is focused on studying the influence of rainfall intensity and slope on the development of rills and rill characteristics of the soil slopes $[1,2]$. The development of rill networks varies $[3,4]$, and trichomonas point, rill head extension time, and average head erosion rate are representative indicators that reflect rill development better than the other indicators [5]. At the same time, the slope velocity is an important parameter for understanding the slope rill erosion process under rainfall conditions [6] and plays an 
important role in the slope rill erosion dynamic process mechanism [7]. In addition, calculation of the hydraulic and hydrodynamic parameters of the slope runoff is crucial for evaluating the degree of slope erosion and the occurrence of debris flow [8-10]. In gravel and gravel mound areas, the gravel content has a significant influence on the hydrodynamic parameters and damage patterns of the slope runoff. Liang et al. [11] studied the relationship between the gravel content of the slope and runoff and sand production. Wang et al. [12] conducted an indoor artificial rainfall simulation to study the erosion process of red soil slopes with different rainfall intensities, slope ratios, and forms of gravel and compared the rainfall runoff time, runoff rate, runoff process, and sediment intensity of each slope. Jiang et al. [13] studied the effects of rainfall intensity and slope on runoff, infiltration, and sediment yield from landslides. Jiang et al. [14] studied the process of erosion and destruction of slope rills under a heavy rainfall. Liu et al. [15] quantified the hydraulic characteristics of the surface water flow on gravel-covered slopes through laboratory flume experiments. Qin et al. [16] used artificial rainfall simulation methods to study kinetic and rill morphological characteristics of erosion by water with different gravel contents and different rainfall intensities. It was concluded that the hydrodynamic parameters were significantly related to the degree of denudation through a power function relationship, and the water flow power had the best correlation. Rahardjo et al. [17] believed that the damage caused by rainfall was mainly through rainwater infiltration; however, the mechanism of rainwater infiltration has not been adequately understood. Therefore, understanding the response of slope soil under different rainfall conditions is crucial. Tahmasebi and Kamrava [18] based on the DEM model. A joined mathematical thermo-hydro-mechanical framework for studying the effects of external forces, the presence of fluid and thermal variation, is presented. The coupled method is based on a combination of Discrete Element Method and Computational Fluid Dynamics for simulating the solid and the fluid-flow, respectively. Researchers analysed the soil-rock distribution characteristics by test pitting, image analysis, and sieve test. Then, the PFC2D random structure models with different rock block size distributions were built. The stress evolution, damage evolution and failure, deformation localization (based on a principle proposed in this paper), rotation of rock blocks, and shear strength were systematically investigated [19]. These provide a theoretical basis for us to study the force, displacement, and movement mode between soil particles and water during rainfall.

The relative percentages of minerals in Anqing clay gravel layer are as follows: illite (12.3\%), kaolinite (47\%), and illite-smectite-mixed (40.7\%); furthermore, the illitesmectite-mixed ratio is $58.3 \%$. The mechanical properties of these hydrophilic minerals vary significantly when exposed to water. Compared to the general soil-rock mixtures, gravel and soil exhibit a better bonding force; however, under the action of rain, this cementing force will be significantly weakened [20]. Furthermore, the size distribu- tion range of gravel in the clay gravel layer is wider, and the gravel content is higher. When studying slope erosion, researchers in the past focused on the shape of the slope rill erosion and its hydrodynamic parameters, and there have been only a few studies on the slope stability during the erosion process.

To mitigate the disasters caused by the instability of the clay gravel layer slope of the Anqing group, it is necessary to conduct research on the erosion mechanism and slope stability of special Anqing group clay gravel sloping surfaces under a rainfall. It is of imminent interest to study the main controlling factors, such as the rainfall intensity, slope ratio, and gravel content on slope erosion damage and slope stability. This study mainly investigates the erosion mechanism of slopes with different slope ratios and different gravel contents under heavy rainfall conditions. It is aimed at providing a reasonable theoretical basis for the protection and treatment of clay gravel slopes.

\section{Materials and Methods}

2.1. Overview of the Sampling Area. The sampling site is located in Wangjiang County, west of the urban area of Anqing City, Anhui Province, China (Figure 1). It has a subtropical and humid monsoon climate along the Yangtze River, with an abundant average rainfall of approximately $1385.0 \mathrm{~mm}$ and average annual temperature of $16^{\circ} \mathrm{C}$. The sampled soil was from the Neogene to early quaternary Pleistocene Anqing group clay gravel layer, mainly distributed on the northern and southern banks of the Anqing section of the Yangtze River and mostly on the highest terraces (the upper part of the base terraces, that is, the fourth-level terraces, with some exposure to the third and second terraces (posts)). The stratum is of river alluvial type and mainly includes the Anqing gravel layer and Wangjiang gravel layer. Figure 2 shows the typical profile of the clay gravel layer. The basic colour of the stratum is yellow or greyish yellow; the layer thickness is $10-20 \mathrm{~m}$; the main lithology is sand gravel with intercalated clay. The typical gravel diameter is $2-7 \mathrm{~cm}$, with a gravel content of $55 \%$ to $75 \%$ (usually greater than $50 \%$ ). The roundness is mainly subcircular, and its sortability is medium. The gravel is mainly composed of quartz gravel, followed by quartz sandstone gravel, siliceous rock gravel, jade, and limestone.

2.2. Test Materials. The clay gravel layer of the Anqing group is composed of gravel and clay with very varying particle sizes. To study the influence of gravel content on the rainfall failure mechanism of the slope, we were required to determine the soil-rock threshold of the clay gravel layer. Medley [21] carried out an extensive statistical analysis and showed that the particle size distribution of soil-rock mixture satisfied self-similarity within different research scales. The conceptual model of soil and rock threshold and rock content proposed by him was highly practical; however, it ignored the overall step-by-step characteristics of particle size. In this study, the fractal geometry theory was used to determine the threshold value of the clay gravel layer. This study adopted by Mandelbrot 


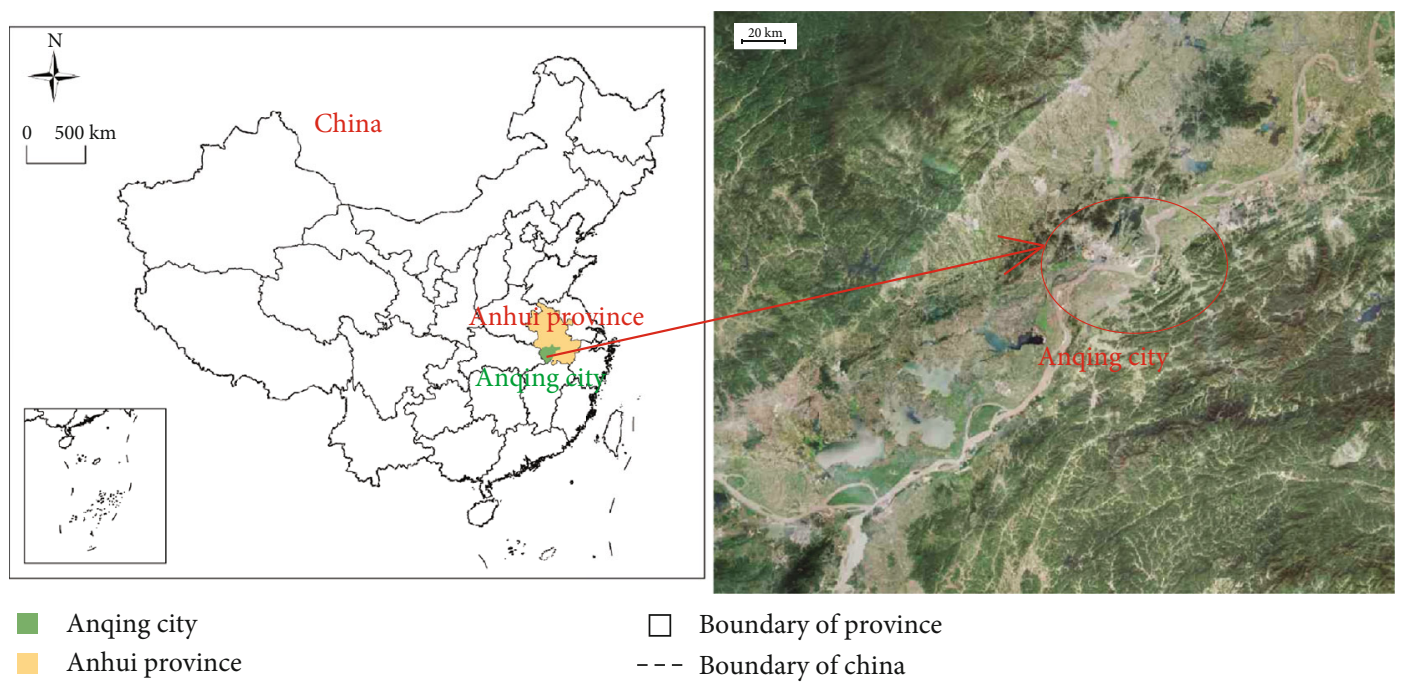

FIgURE 1: Topographic map of the upper reaches of the Wanjiang River in Anhui Province.

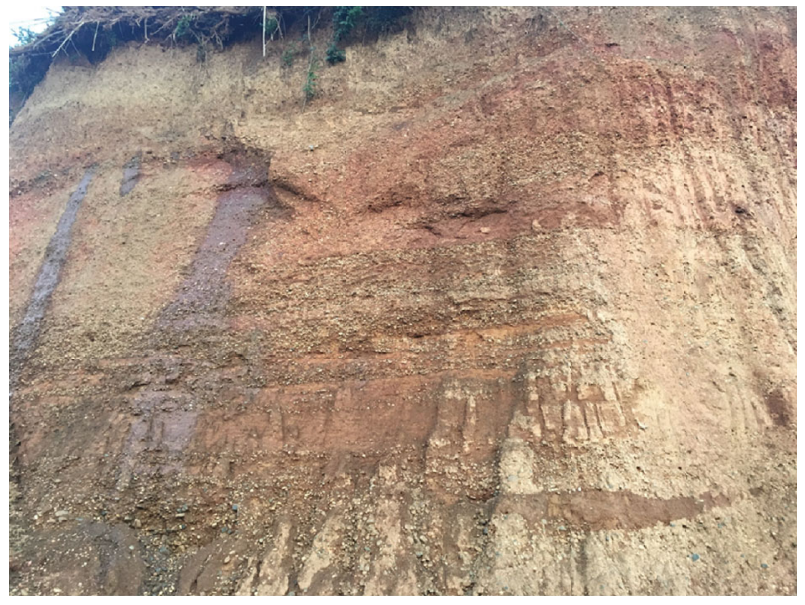

FIGURE 2: Typical profile of clay gravel layer.

[22] was based on the fractal structure expression of particle mass distribution derived from literature [23], and the fractal theory obtained is as follows:

$$
\frac{M(d<r)}{M_{T}}=\left(\frac{r}{r_{L}}\right)^{3-D} .
$$

Here, $M_{T}$ and $r_{L}$ represent the total mass and maximum particle size of the particle system, $M(d<r)$ refers to the total mass with the particle size $d<r$, respectively, and $(3-D)$ is the power exponent; $d$ represents the radius of the particle; $r$ represents the particle size; $D$ is the fractal dimension. This formula represents the power function relationship between the mass fraction and the particle size ratio. The grain-size distribution of clay gravel layer at the sampling point was analysed, and the grain-size accumulation curve was denoted as PSD1, PSD2, and average PSD, as shown in Figure 3. In this experiment, two sets of particle size cumulative curves were selected for screening and were recorded as PSD1 and PSD2; the average PSD of the gradation curve was obtained by averaging these two sets to calculate the fractal dimension, and the same was used in Equation (1). The mass cumulative percentage curve and the double logarithmic coordinate curve of the particle size are shown in Figure 4. It can be seen from the figure that the particle size distribution curve of the clay gravel layer did not satisfy a strict linear relationship within the research scale. With $r=5 \mathrm{~mm}$ as the point of separation, there was a strict scale-free interval on either side. The corresponding fitting formulae were $y_{1}=0.71 x+1.16$ and $y_{2}=0.28+1.46$; the corresponding fractal dimensions were $D_{1}=2.29$ and $D_{2}=2.72$, respectively. This shows that the particle size distribution of the clay gravel layer had a twofold fractal structure. Originally, " $r=5 \mathrm{~mm}$ " was considered as the "soil threshold" of the clay gravel layer.

2.3. Test Plan. From actual engineering experience and related results of rainfall erosion and destruction of soil slopes, the gravel content, slope ratio, and rainfall intensity all are considered to have an impact on the failure mechanism of clay gravel slopes. If the above three factors are comprehensively considered for a comprehensive test, 27 tests are required. Large-scale model tests can be expensive and entail time costs. Therefore, a more scientific, reasonable, and efficient orthogonal test method was adopted [24]. This method can design a variety of orthogonal tables for the tests, considering different factors and levels; it can screen several comprehensive tests according to certain mathematical rules and select nine typical tests from 27 tests. The orthogonal test scheme is shown in Table 1.

2.4. Test Device. The scouring device was composed of four components, as shown in Figure 5: the rainfall system, scour collection system, slope system, and camera system. The rainfall system could control the rainfall area according to the scope of the test and adjust the rainfall intensity, for example, light rain, heavy rain, and heavy rain in nature. At the same time, the uniformity of rainfall could reach more 


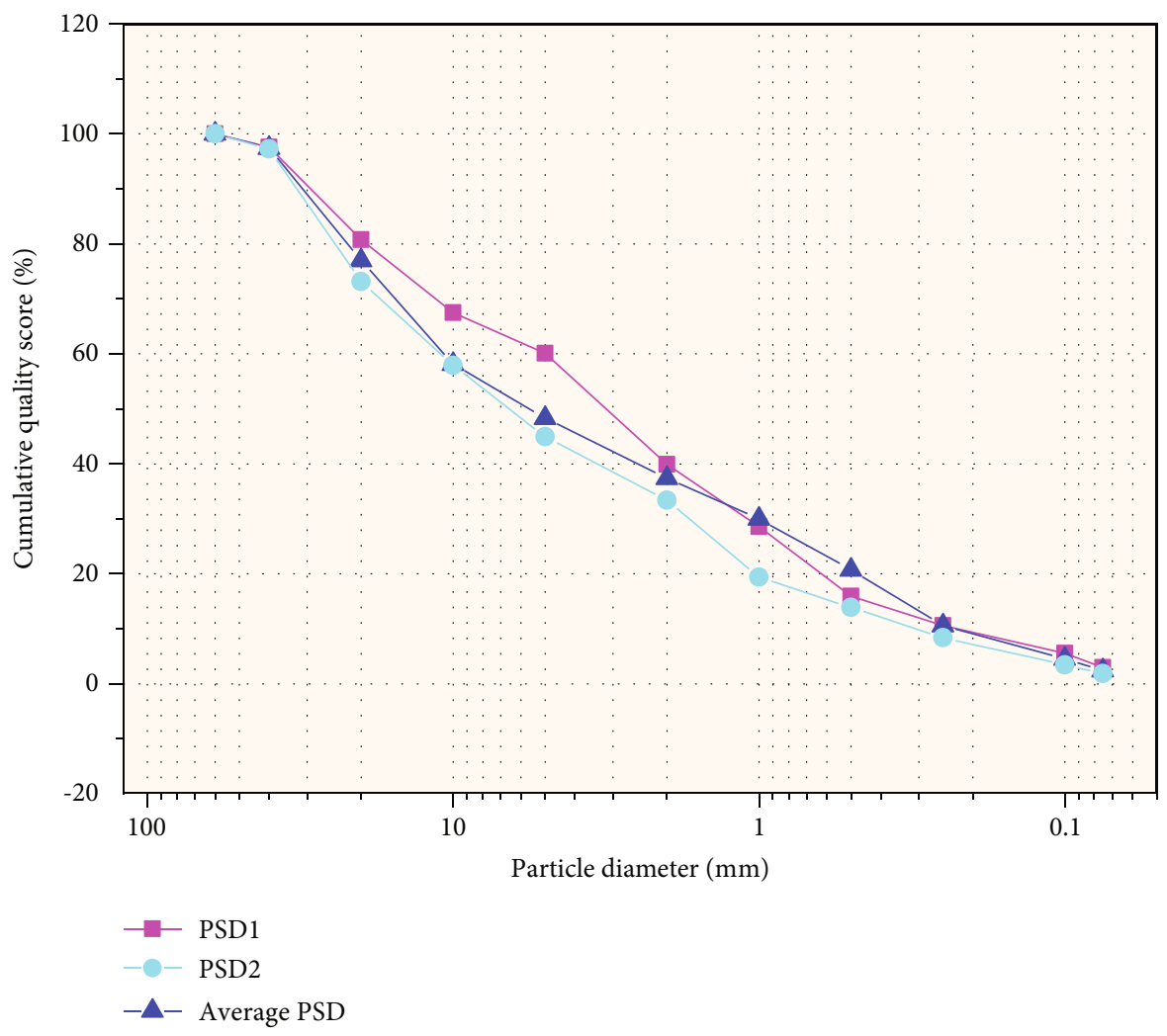

Figure 3: Nature grain-size distribution curve of clay gravel layer.

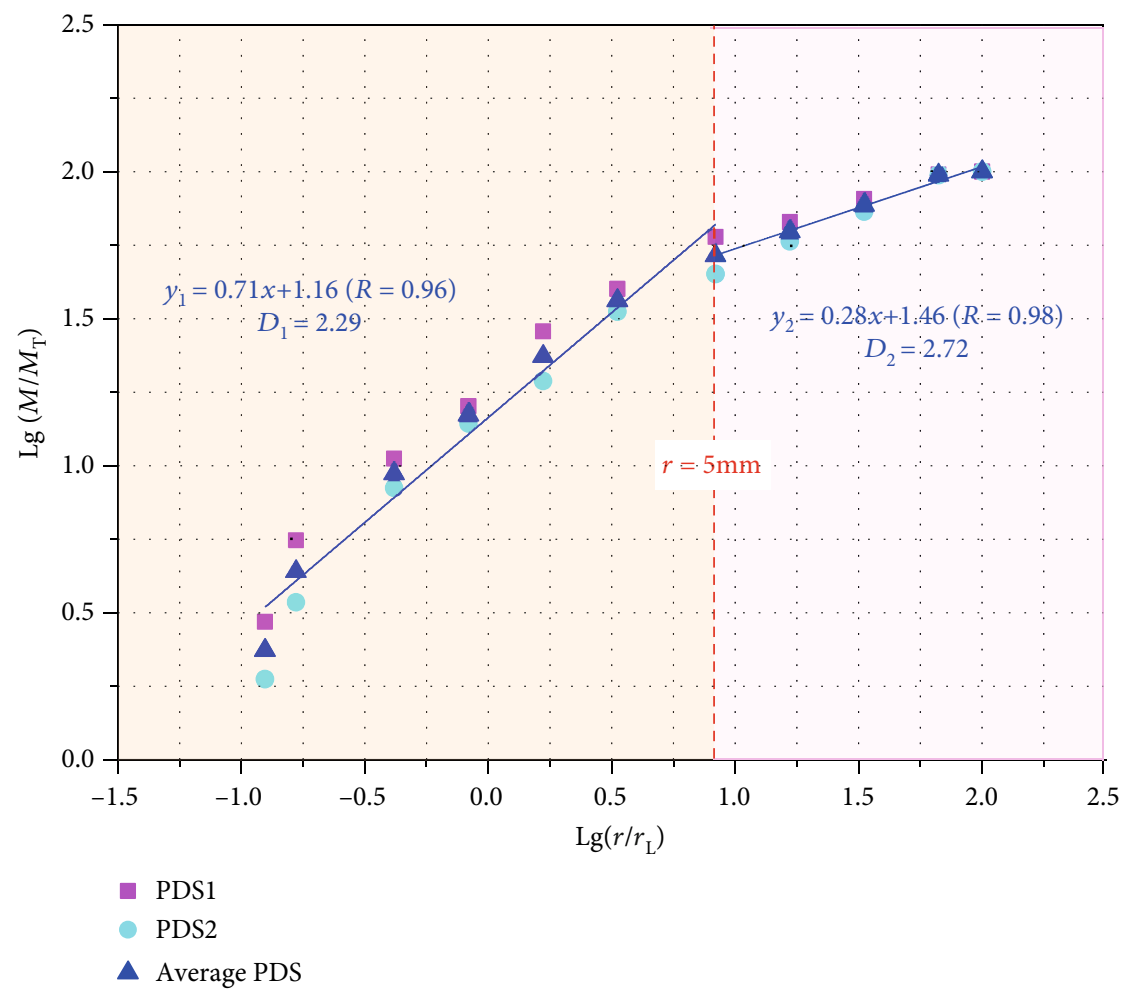

Figure 4: Calculation of the fractal dimension of the grain size of clay gravel and its analysis. 
TABLE 1: Orthogonal test scheme.

\begin{tabular}{lccc}
\hline Test number & $\begin{array}{c}\text { Gravel } \\
\text { content }(\%)\end{array}$ & Slope ratio & $\begin{array}{c}\text { Rainfall } \\
\text { intensity }(\mathrm{mm} / \mathrm{h})\end{array}$ \\
\hline A & 30 & $1: 0.5$ & 180 \\
B & 50 & $1: 0.5$ & 100 \\
C & 70 & $1: 0.5$ & 140 \\
D & 30 & $1: 1.5$ & 100 \\
E & 50 & $1: 1.5$ & 140 \\
F & 70 & $1: 1.5$ & 180 \\
G & 30 & $1: 2.5$ & 140 \\
H & 50 & $1: 2.5$ & 180 \\
I & 70 & $1: 2.5$ & 100 \\
\hline
\end{tabular}

than $85 \%$, and the sprayed water was similar to raindrops. The scour collection system could collect the mixture of rainwater and clay gravel, use an electronic scale to weigh the total mass of the scoured material, and then dry the saturated soil in an oven until the mass remained constant from which the dry mass was finally weighed. Using this system, the runoff rate and infiltration rate at different times could be calculated, and the total mass of the scoured material from the slope could also be obtained. The slope system comprised a model box with a variable slope ratio. The system could simulate a complete slope, including the slope top, slope surface, and slope angle. The width and length of the slope were 1 and $1.5 \mathrm{~m}$, respectively. The camera system used a digital camera to capture the appearance of the slope at different times. Image recognition was used to extract the distribution of gullies on the slope as well as their depth and width. Thus, the development trend and change process of gullies at different times were studied. Through image processing slope surface images of different times, observe the change of slope failure, for analysis of slope rainfall erosion failure mechanism that provides a comprehensive efficient and strong operability, wide applicability, and can be more realistic simulation of the natural slope damage under different rainfall intensities, to clarify the slope rainfall erosion failure mechanism that provides an effective method and to lay a good foundation for the management of soil and water loss and the protection of the slope stability.

2.5. Test Procedure. The test procedure consisted of the following steps:

(1) The clay gravel layer was retrieved from Wangjiang County to the west of Anqing city, and the matrix moisture content of the in situ clay gravel was measured to be $12.5 \%$. In addition, the average value of the natural density of the clay gravel was measured to be $1.93 \mathrm{~g} / \mathrm{cm}^{3}$

(2) The retrieved sample was dried and slightly ground so that there was no cementation between the clay and gravel. It was then passed through a $5 \mathrm{~mm}$ diameter sieve to separate the clay and gravel
(3) According to the volume of the model box and the density of the clay gravel layer, the total mass of the clay gravel was calculated; the matrix moisture content of the clay gravel was controlled to $12.5 \%$ to ensure that the mechanical properties of the clay gravel were closer to those of the original soil. Based on the range of gravel content employed in the experiment, the water was weighed, with clay and gravel to obtain a corresponding quality

(4) The clay and gravel were mixed with each other in required proportions; water of appropriate quality was sprayed evenly with a kettle. The stirring was repeated to ensure that the water content of the clay gravel matrix was evenly distributed

(5) Using the layered filling method, the clay gravel was divided into several layers for filling. Each layer was filled with clay gravel of appropriate quality and then compacted to the original soil density. A PR2/4 soil profile moisture measuring instrument was buried successively at the top, two-thirds distance from the top, and one-third distance from the top of the slope

(6) With regard to the rainfall, the corresponding rainfall intensity in the system was set, and the total rainfall time was $1 \mathrm{~h}$ (if the slope had a large area of collapse and instability, the test was terminated early)

(7) The scoured material was collected every five minutes, and its mass was weighed. Then, the scoured material was allowed to stand still; the supernatant liquid was discarded; the remaining clay gravel was dried in an oven at $105^{\circ} \mathrm{C}$. The clay gravel was weighed again, which was subtracted from the total mass to calculate the mass of the water. The total mass of the slope runoff was calculated back to calculate the slope runoff rate, and then, the slope infiltration rate was calculated by subtracting the slope runoff rate from the rainfall intensity

(8) A digital camera was used to photograph the slope every five minutes to observe the changes in the width, depth, shape, number, and distribution of the gullies on the slope

(9) After the rainfall, a slope water content measuring instrument was used to measure the matrix water content of the slope to obtain the immediate matrix water content after the rainfall. Then, the slope was allowed to stand for $24 \mathrm{~h}$, and then, the matrix moisture content of the slope was measured

\section{Erosion Failure Form of the Clay Gravel Slope}

3.1. Slope Failure Morphological Characteristics. Figure 6 shows the slope failure morphology diagram for different test configurations. The slope of the test group with slope ratios of $1: 2.5$ and $1: 1.5$ was defined as a gentle slope, and the slope of the test group with a slope ratio of $1: 0.5$ was defined as a steep slope. The damage patterns of the slope surface of the 


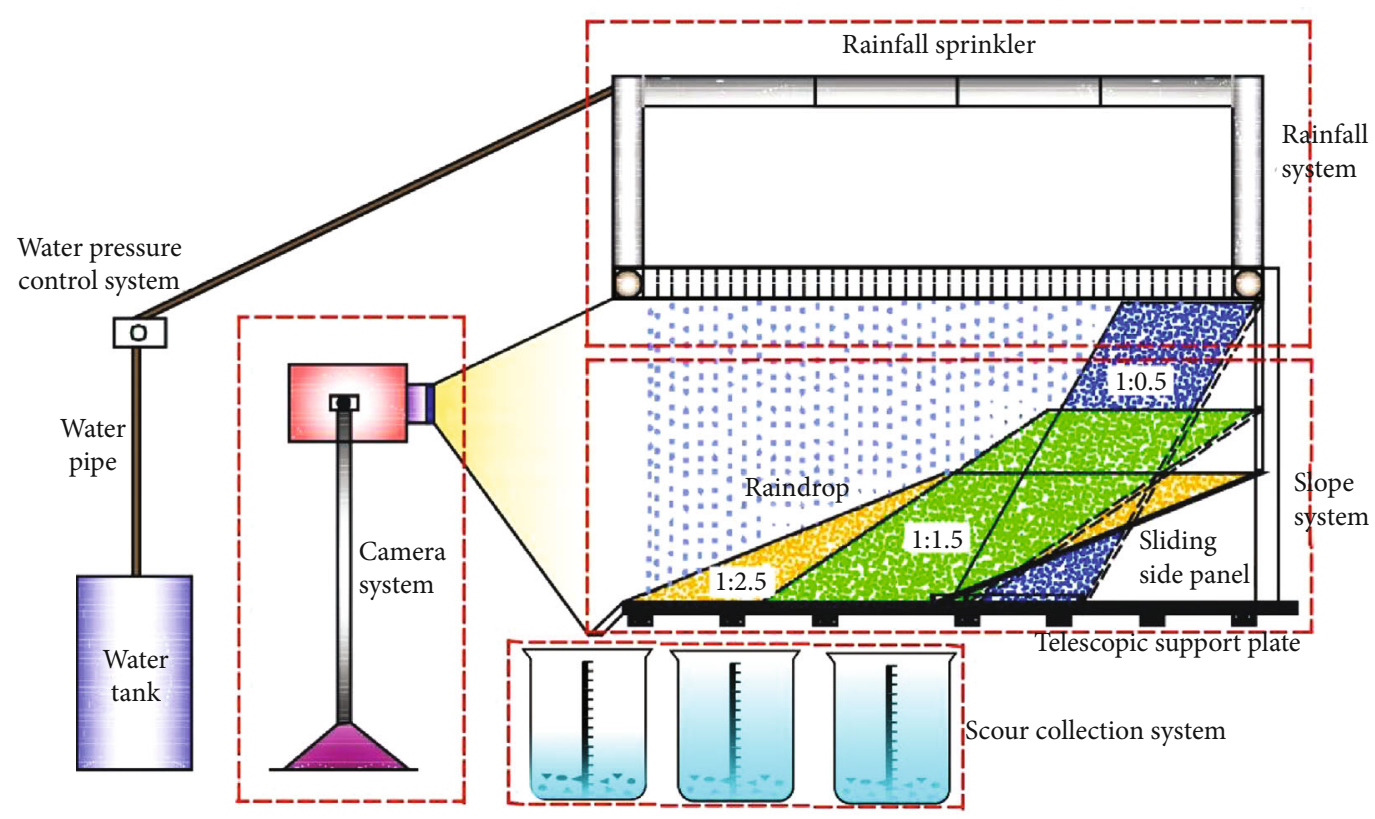

Figure 5: Schematic diagram of the test setup.

gentle slope of the clay gravel layer under different gravel contents, slope ratios, and rainfall intensities after $1 \mathrm{~h}$ of rainfall are shown in Figures 6(a)-6(f). It can be seen from the figure that the forms of gullies and pits on gentle slopes were affected by the gravel content. At the same time, the spatial distribution of gravel affected the position of the gullies and pits on the slope. The intensity of rainfall affected the depth of the gullies and size of the pits. Under different gravel contents, slope ratios, and rainfall intensities of the clay gravel steep slope, the slope failure patterns are displayed in Figures 6(g)-6(i). It can be seen from the figure that the difference in the gravel content determined the failure form of the slope. The steep slope with a low gravel content (30\%) suffered a gully failure, and the steep slope with a high gravel content (50\% and 70\%) suffered "slip-by-layer" failure. However, upon comparing the damage patterns of gentle and steep slopes, it can be seen that the slope ratio was a key factor affecting the stability of the clay gravel sloping surface under rainfall conditions.

3.2. Gentle Slope Failure Form. The degree of damage at different positions of the slope surface is defined as $\omega_{l}=w_{l} / w_{0}$ $\left(\omega_{l}\right.$ is the degree of damage of the slope surface; its value ranges from 0 to 1 and is a dimensionless constant; $w_{l}$ is the width of the pit or rill on the slope when the distance from the point to the bottom of the slope is $l$, in centimeter; $w_{0}$ is the width of the slope when the distance from the bottom of the slope is $l$, in centimeter).

Figure 7 shows the degree of damage curves for different positions on the gentle slopes. It can be seen from the figure that under different gravel contents, slope ratios, and rainfall intensities, the degree of damage of the clay gravel sloping surface increased from the top to the bottom of the slope. In the gentle slope tests, when the rainfall intensity at different positions on the slope was the same, the rainfall from the top of the slope to the bottom of the slope increased successively. The greater the rainfall on the slope, the greater the erosion damage to the slope. The curve was close to the bottom of all the curves, and the test E curve was close to the top of all the curves. It shows that the overall degrees of erosion of the slope in experiment I and experiment E were the smallest and the largest, respectively, among the gentle slope erosion tests. At the same time, the scours in experiment I and experiment $\mathrm{E}$ were the smallest and largest, respectively, in the gentle slope tests. This shows that the lower the overall erosion degree of the slope, the smaller the total mass of the scoured material, which would reflect the overall degree of erosion of the slope.

3.3. Steep Slope Failure Form. The shape of the erosion failure of the clay gravel slope was related to the gravel content, when the gravel content was $30 \%$. For this case, the failure of the slope was a gully failure, which was similar to that of a gentle slope. At the beginning of the rainfall and before the runoff occurred, splash erosion on the slope played a major role. As the rainfall progressed, surface currents were formed and sheet erosion occurred. Then, the crater formed by the flaky erosion of the surface flow gradually transformed into a concentrated flow. On the path of the concentrated water flow, the erosion force of runoff gradually increased, and when soil particles could be washed away, a small waterfall was formed. The cascade further developed and evolved into a rill head, and rill erosion occurred accordingly. The side-cutting erosion of the head of the rill, forward erosion, and collapse and erosion of the ditch wall caused a discontinuity of the ditch. Therefore, multiple discontinuous rills on the same concentrated flow channel were connected by vertical erosion to form continuous rills. With the development of rainfall and rill erosion, the rill dip, rill density, degree of rill stripping, and bending complexity of the rills increased. 


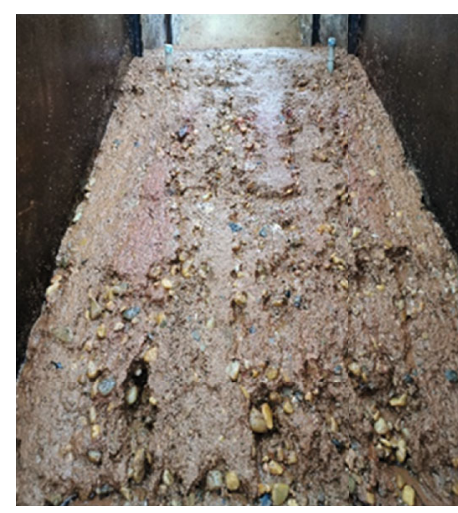

(a)

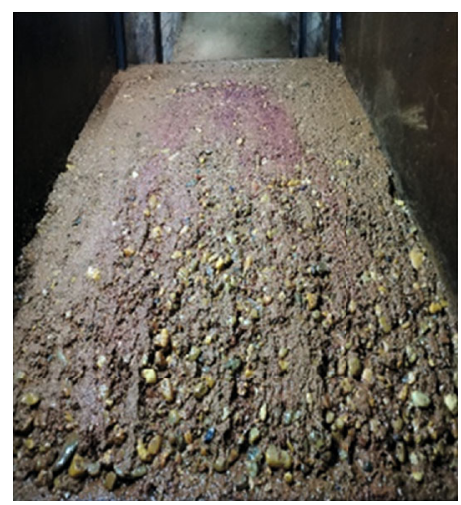

(c)

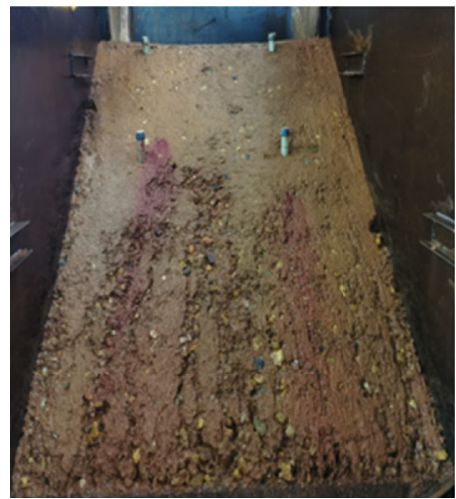

(e)

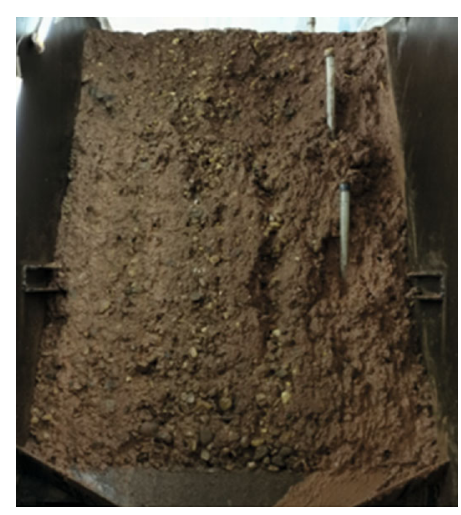

(g)

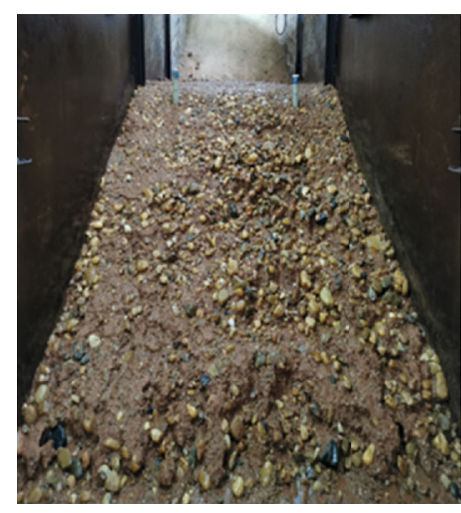

(b)

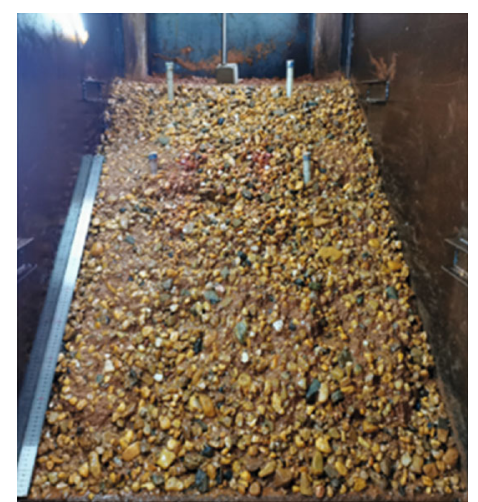

(d)

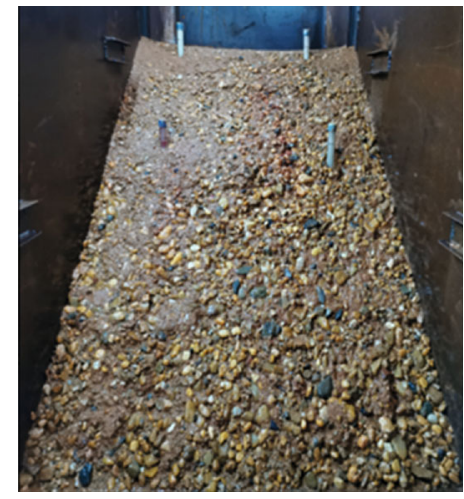

(f)

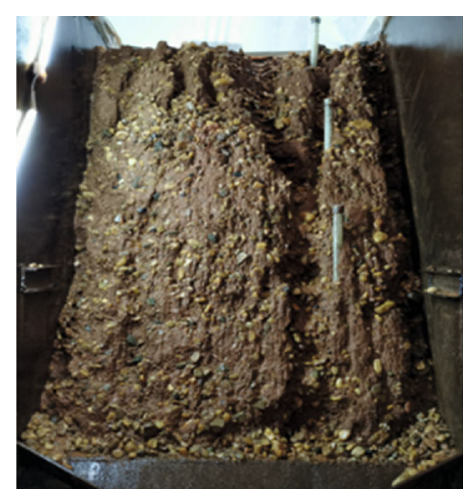

(h)

Figure 6: Continued. 


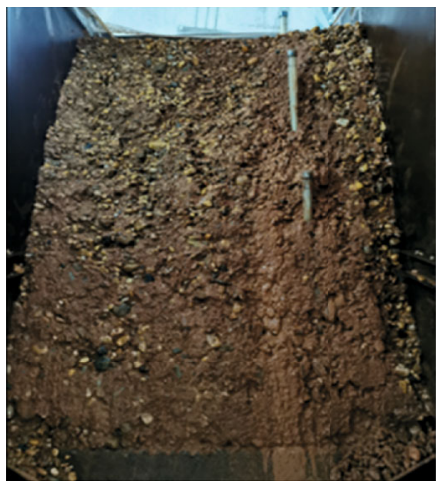

(i)

FIGURE 6: Slope morphology diagram at the end of slope erosion: (a) 30\%-1 :2.5-140 (1 h); (b) 50\%-1:2.5-180 (1 h); (c) 70\%-1 :2.5-100 (1 h); (d) 70\%-1:1.5-180 (1 h); (h); (e) 30\%-1:1.5-100 (1 h); (f) 50\%-1:1.5-180 (1 h); (g) 50\%-1:0.5-100 (20 min); (h) 30\%-1:0.5-180 (1 h); (i) 70\%-1 : 0.5-140 (13 min).

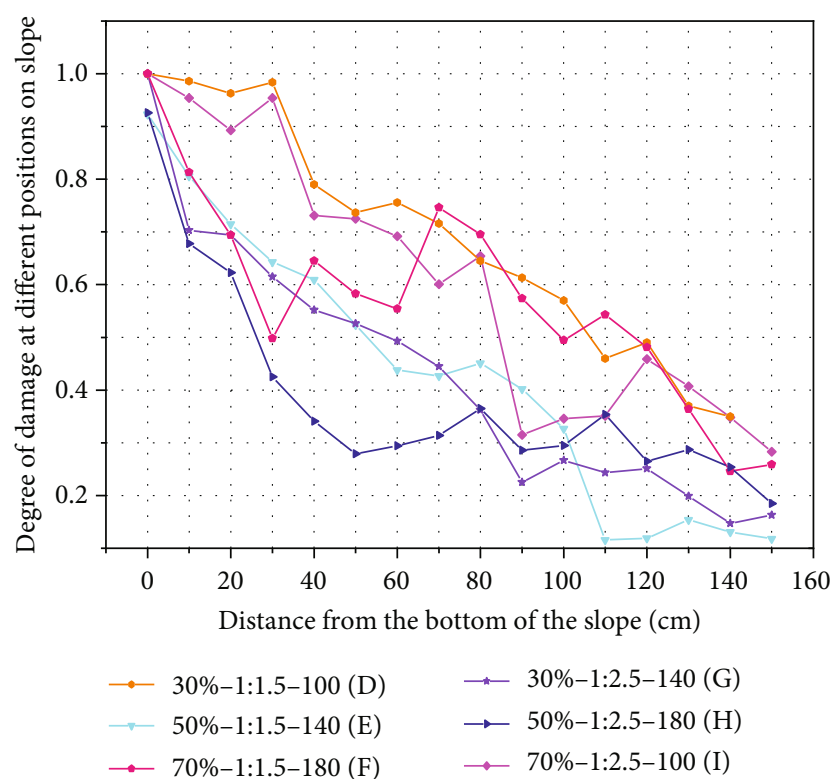

FIGURE 7: Curves representing the degree of damage at different positions of slope.

When the gravel content was either $50 \%$ or $70 \%$, there was a significant difference in the failure mode of the sloping surface and the damage mode, compared to the case of $30 \%$ gravel content; there was almost no evidence of gullies forming on the slope surface. The sloping surface presented the failure form of "layer-by-layer" sliding mode. The reason was as follows: when the gravel content was high, initial cracks were formed between the gravel and the clay, which was the dominant channel for water seepage. At the same time, when the water flowed through a junction, a vortex with a stronger denudation capacity was formed, which would wash away the clay beside the gravel, and the gravel would fall into the erosion pit to form small steps under the action of gravity. These small steps consumed the energy of the runoff scouring in the vertical direction and hindered the runoff in that direction. At the same time, it promoted a lateral flow of water, increased the lateral erosion ability of the water, and brought the vertical and lateral runoff forces at different positions of the slope close to each other, so that the degree of damage at different positions of the slope was similar. The phenomenon of "layer collapse" destroyed this form.

When the gravel content exceeds $70 \%$, the failure mode of clay gravel slope is different from the previous two failure modes. Because the gravel content is sufficient, the gravel contacts each other to form a stable skeleton structure. The clay is filled in the pores of the gravel. When the clay is washed away, the skeleton structure of the slope is not affected much, and the stability of the slope is almost unchanged. In this case, the main factor affecting the stability of the slope is the slope ratio, because the change of slope ratio affects the stability of gravel and thus the stability of slope.

\section{Runoff and Infiltration Characteristics of Clay Gravel Slope}

4.1. Relationship between Slope Runoff, Infiltration, and Rainfall Time. Figures 8 and 9 show the simulated artificial rainfall, clay gravel layer slope runoff rate, and infiltration rate curves with time under different conditions. Under the conditions of different gravel contents, slope ratios, and rainfall intensities, the runoff rate and infiltration rate of the clay gravel layer slope changed similarly. When the rainfall time was less than $10 \mathrm{~min}$, the slope runoff was in a rapid growth stage. When the rainfall time was more than $10 \mathrm{~min}$, the slope runoff was in a stable stage; finally, when the rainfall time was less than $10 \mathrm{~min}$, the slope infiltration was in a declining stage. When the rainfall time was more than $10 \mathrm{~min}$, the slope infiltration is in the stable stage. At the beginning of the rainfall, the clay gravel slope was not sealed by water, and the erosion of the slope was mainly by raindrop splash erosion. Therefore, the slope runoff rate at this time was less than the later runoff rate, and the slope infiltration rate was greater than the later infiltration rate. With the formation of the slope water flow to promote the water sealing effect of the 

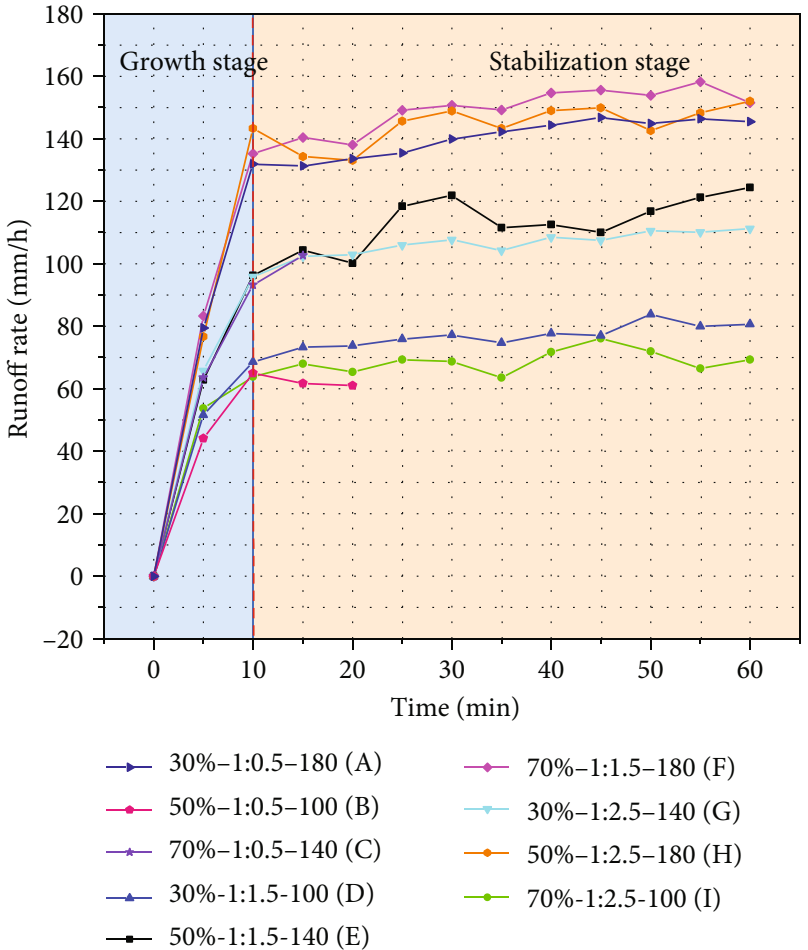

FigurE 8: Runoff rate of the clay gravel slope.

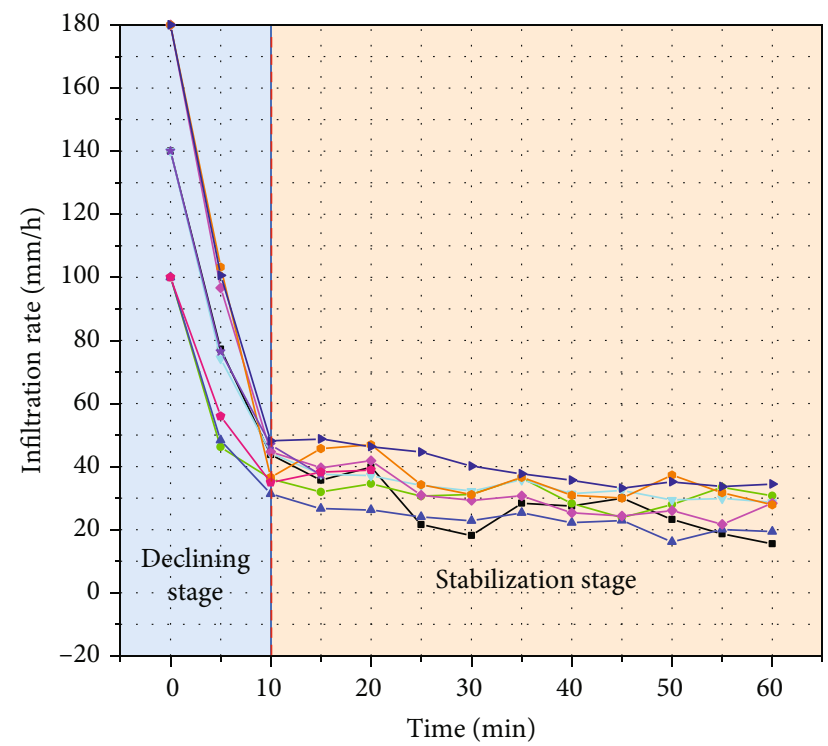

$$
\begin{array}{ll}
\rightarrow \text { 30\%-1:0.5-180(A) } & \rightarrow-70 \%-1: 1.5-180(\mathrm{~F}) \\
\rightarrow-50 \%-1: 0.5-100(\mathrm{~B}) & \rightarrow-30 \%-1: 2.5-140(\mathrm{G}) \\
\rightarrow-70 \%-1: 0.5-140(\mathrm{C}) & \rightarrow-50 \%-1: 2.5-180(\mathrm{H}) \\
\rightarrow-30 \%-1: 1.5-100(\mathrm{D}) & \rightarrow-70 \%-1: 2.5-100(\mathrm{I}) \\
\rightarrow-50 \%-1: 1.5-140(\mathrm{E}) &
\end{array}
$$

FIgURE 9: Infiltration rate of the clay gravel layer slope.

slope, the infiltration rate of the clay gravel slope gradually decreased, and the runoff rate gradually increased. When the rainfall time was approximately $10 \mathrm{~min}$, the slope runoff
TABLE 2: Analysis of influencing factors of runoff rate in stable stage.

\begin{tabular}{lcccc}
\hline $\begin{array}{l}\text { Test } \\
\text { number }\end{array}$ & $\begin{array}{c}\text { Gravel } \\
\text { content } \\
(\%)\end{array}$ & $\begin{array}{c}\text { Slope } \\
\text { ratio }\end{array}$ & $\begin{array}{c}\text { Rainfall } \\
\text { intensity } \\
(\mathrm{mm} / \mathrm{h})\end{array}$ & $\begin{array}{c}\text { The stable runoff } \\
\text { rate }(\mathrm{mm} / \mathrm{h})\end{array}$ \\
\hline $\mathrm{A}$ & 30 & $1: 0.5$ & 180 & 140.2 \\
$\mathrm{~B}$ & 50 & $1: 0.5$ & 100 & 62.6 \\
$\mathrm{C}$ & 70 & $1: 0.5$ & 140 & 97.9 \\
$\mathrm{D}$ & 30 & $1: 1.5$ & 100 & 76.6 \\
$\mathrm{E}$ & 50 & $1: 1.5$ & 140 & 112.5 \\
$\mathrm{~F}$ & 70 & $1: 1.5$ & 180 & 148.8 \\
$\mathrm{G}$ & 30 & $1: 2.5$ & 140 & 106.1 \\
$\mathrm{H}$ & 50 & $1: 2.5$ & 180 & 144.6 \\
$\mathrm{I}$ & 70 & $1: 2.5$ & 100 & 68.6 \\
$\mathrm{~T} 1$ & 322.9 & 300.7 & 207.8 & \\
T2 & 319.7 & 337.9 & 316.5 & \\
$\mathrm{~T} 3$ & 315.3 & 319.3 & 433.6 & \\
$\mathrm{~m} 1$ & 107.63 & 100.23 & 69.27 & \\
$\mathrm{~m} 2$ & 106.57 & 112.63 & 105.5 & \\
$\mathrm{~m} 3$ & 105.1 & 106.43 & 144.53 & \\
$R$ & 2.53 & 12.40 & 75.27 & \\
\hline
\end{tabular}

Note that the "T1" line gives the sum of the average rates of the three tests in the stable phase under the condition of $30 \%$ gravel content; $\mathrm{T} 1=140.2+$ $76.6+106.1=322.9$, and the average value $=\mathrm{T} 1 / 3=322.9 / 3=107.63$; it is listed in "m1." Similarly, the average runoff rates of the three tests under $50 \%$ and $70 \%$ gravel content were 106.57 and 105.1 , respectively. The ranges of the three average values were $R=\max [107.63,106.57,105.1$ $\min ][107.63,106.57,105.1]=2.53$, which is listed in the last row of the table. Corresponding numbers for the slope ratio and rainfall intensity were calculated similarly.

rate and infiltration rate reached relatively stable values. In the stable stage of the slope runoff, the runoff rate fluctuated over a small range, mainly owing to the unstable development of the slope erosion rills, for example, the widening of the rills, collapse of ditch walls, and blocking effect of gravel falling into the rills on runoff.

4.2. Analysis of Influencing Factors of Slope Runoff Rate in the Stable Stage. Table 2 summarizes the results from the analysis of the influencing factors of the runoff rate of the clay gravel layer sloping surface under different gravel contents, rainfall intensities, and slope ratios. It was assumed that the average value of the runoff rate in the stable stage with time was the stable runoff rate. The influences of gravel content, slope ratio, and rainfall intensity on the stable runoff rate were analysed. The $R$ value of each factor in Table 2 indicates the maximum differences. The larger the range, the greater the influence of this factor on the stable runoff rate. Therefore, the order of the degrees of influence on the stable runoff rate was rainfall intensity $>$ slope ratio $>$ gravel content. Figure 10 shows the relationship between the average stable runoff rate and the gravel content, slope ratio, and rainfall intensity. It can be seen from the figure that as the gravel content increased, the average stable runoff rate kept decreasing. As the slope ratio increased, the average stable runoff rate first increased and then decreased. With an increase in the rainfall 


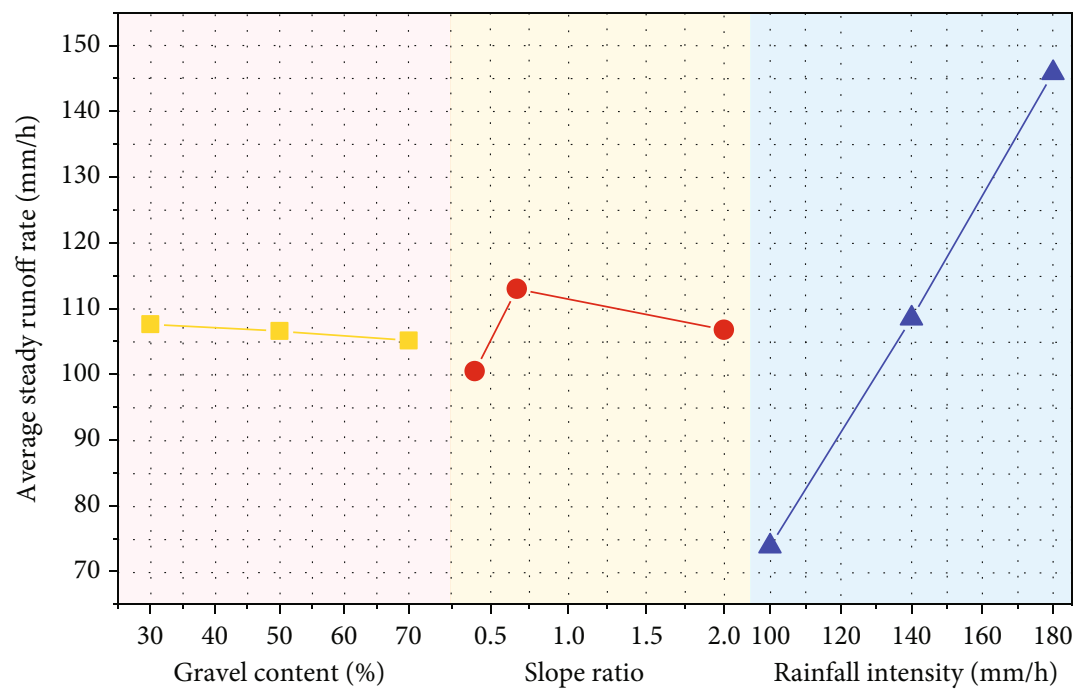

FIGURE 10: Relationship between the average steady runoff rate and gravel content, slope ratio, and rainfall intensity.

intensity, the average steady runoff rate kept increasing. Therefore, when the rainfall intensity was constant, the most favourable combination of the gravel content and slope ratio for a stable runoff of the slope was $30 \%-1: 1.5$. Under these conditions, the clay completely wrapped the gravel, and the gravel was embedded in the clay to form a compact structure. More runoff energy was needed to wash away the soil particles. In addition, the presence of gravel hindered the infiltration channels for the rainwater, and the slope was not conducive to the infiltration of rainwater. At the same time, the slope ratio of $1: 1.5$ was larger for the gentle slope, which was beneficial to the runoff of the slope. The interaction of these three factors promoted a direct flow of rainwater along the sloping surface, and at the same time, there were fewer soil particles entrapped in the runoff; therefore, the degree of slope damage was low, and the slope stability was high.

\subsection{Analysis of Influencing Factors of Slope Infiltration Rate} in the Stable Stage. Table 3 summarizes the influencing factor analysis of the infiltration rate of the clay gravel slope under conditions of different gravel contents, rainfall intensities, and slope ratios. Assuming that the stable infiltration rate was the average value of the infiltration rate in the stable phase over time, Table 3 summarizes the influence of gravel content, slope ratio, and rainfall intensity on the stable infiltration rate. The $R$ value of each factor in Table 3 indicates the extreme differences. The larger the range, the greater the influence of this factor on the stable infiltration rate. Therefore, the order of the degrees of influence on the stable infiltration rate was slope ratio $>$ rainfall intensity $>$ gravel content. Figure 11 shows the relationship between the average stable infiltration rate and gravel content, slope ratio, and rainfall intensity. It can be seen from the figure that as the gravel content increased, the average stable infiltration rate increased. This result is consistent with previous research [25]; as the slope ratio increased, the average stable infiltration rate increased. The infiltration rate first decreased and
TABLE 3: Analysis of the influencing factors of the infiltration rate in stable stage.

\begin{tabular}{lcccc}
\hline $\begin{array}{l}\text { Test } \\
\text { number }\end{array}$ & $\begin{array}{c}\text { Gravel } \\
\text { content } \\
(\%)\end{array}$ & $\begin{array}{c}\text { Slope } \\
\text { ratio }\end{array}$ & $\begin{array}{c}\text { Rainfall } \\
\text { intensity } \\
(\mathrm{mm} / \mathrm{h})\end{array}$ & $\begin{array}{c}\text { The stable runoff } \\
\text { rate }(\mathrm{mm} / \mathrm{h})\end{array}$ \\
\hline $\mathrm{A}$ & 30 & $1: 0.5$ & 180 & 39.8 \\
$\mathrm{~B}$ & 50 & $1: 0.5$ & 100 & 37.4 \\
$\mathrm{C}$ & 70 & $1: 0.5$ & 140 & 42.1 \\
$\mathrm{D}$ & 30 & $1: 1.5$ & 100 & 23.4 \\
$\mathrm{E}$ & 50 & $1: 1.5$ & 140 & 28.91 \\
$\mathrm{~F}$ & 70 & $1: 1.5$ & 180 & 31.2 \\
$\mathrm{G}$ & 30 & $1: 2.5$ & 140 & 33.9 \\
$\mathrm{H}$ & 50 & $1: 2.5$ & 180 & 35.4 \\
$\mathrm{I}$ & 70 & $1: 2.5$ & 100 & 31.4 \\
T1 & 97.1 & 119.3 & 92.2 & \\
T2 & 101.71 & 83.51 & 104.91 & \\
T3 & 104.7 & 100.7 & 106.4 & \\
$\mathrm{~m} 1$ & 32.37 & 39.77 & 30.73 & \\
$\mathrm{~m} 2$ & 33.90 & 27.84 & 34.97 & \\
$\mathrm{~m} 3$ & 34.9 & 33.57 & 35.46 & \\
$R$ & 2.53 & 11.93 & 4.73 & \\
\hline
\end{tabular}

Note: $\mathrm{T} 1, \mathrm{~T} 2, \mathrm{~T} 3, \mathrm{~m} 1, \mathrm{~m} 2, \mathrm{~m} 3$, and $R$ have the same meanings and methods as in Table 2 .

then increased; with an increase in the rainfall intensity, the average steady infiltration rate gradually increased; however, the rate of increase gradually decreased. It is generally believed that the infiltration rate of the soil slopes decreased with an increase in the slope ratio; that is, the infiltration rate of the steep slopes was less than that of the gentle slopes. However, the conclusion drawn in this study was that the steeper the slope, the greater the infiltration rate. The main reason for this phenomenon was that this test was carried 


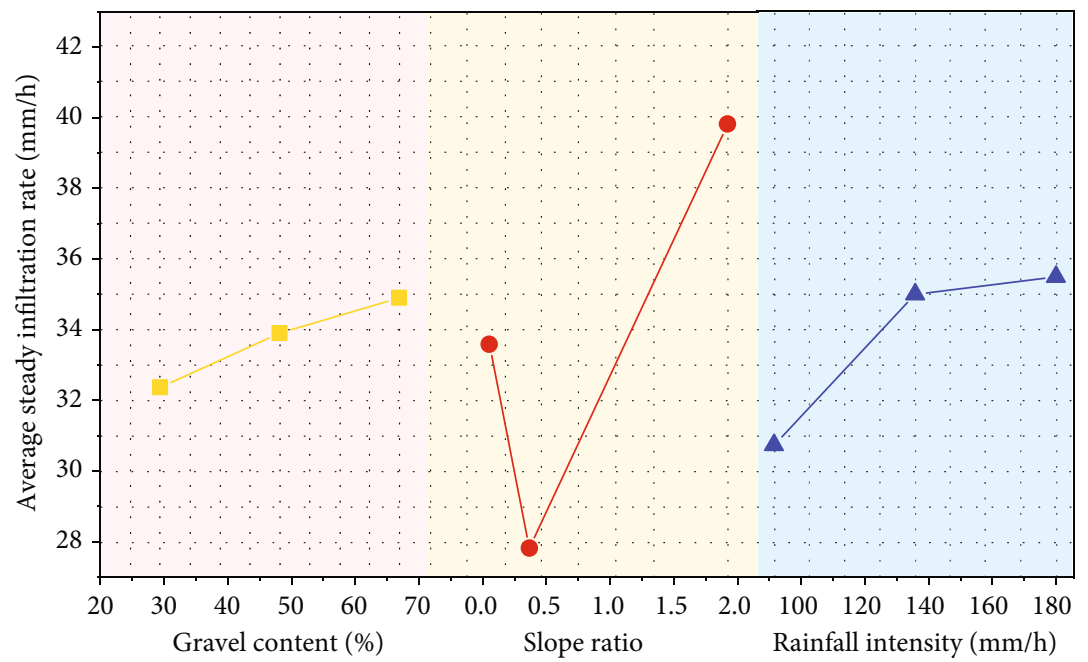

FIGURE 11: Relationship between the average steady infiltration rate and gravel content, slope ratio, and rainfall intensity.

out under heavy rain conditions. The slope of the clay gravel layer quickly formed pits and gullies under rainwater erosion, with an increase in the slope ratio, the pit area of the slope, and the width and depth of the gully expanded rapidly, and even landslides appeared to some extent. The fissures formed by these pits and gullies provided infiltration channels for further infiltration of rainwater. At the same time, the relative surface area of the slope increased, which increased the effective area of infiltration. As a result, the steeper the slope, the greater the infiltration rate. Therefore, when the rainfall intensity was constant, the combination of gravel content and slope ratio, which was most conducive to stable infiltration of the slope, was $70 \%-1: 0.5$. Under these conditions, the slope was most conducive to the infiltration of rainwater, the total mass of the slope-scouring material was the largest, and the slope stability was the lowest.

\section{Scouring Characteristics of Clay Gravel Slope}

5.1. Relationship between the Total Mass of Scoured Material on Gentle Slope, Gravel Content, and Rainfall Intensity. The quality of the scoured material of the clay gravel layer slope increased with an increase in rainfall time. When the slope was gentle, the quality of the scoured material was low, and there was almost no gravel; on the steep slope, the quality of the scoured material was larger and contained a significant amount of gravel. The slope was a key factor for the significant difference in the quality of the washed material.

Figure 12 shows the variation in the total mass of the scoured material over time on the clay gravel slope under artificial rainfall conditions. It can be seen from the figure that with an increase in the slope and rainfall intensity, the erosion force of the runoff increased; the erosion degree of the slope of different clay gravel layers increased, and the quality of the collected erosion material increased significantly. This was consistent with the research results of Jiang et al. [26]. Further analysis of the total mass of the scoured material of the clay gravel layer slope over time under differ-

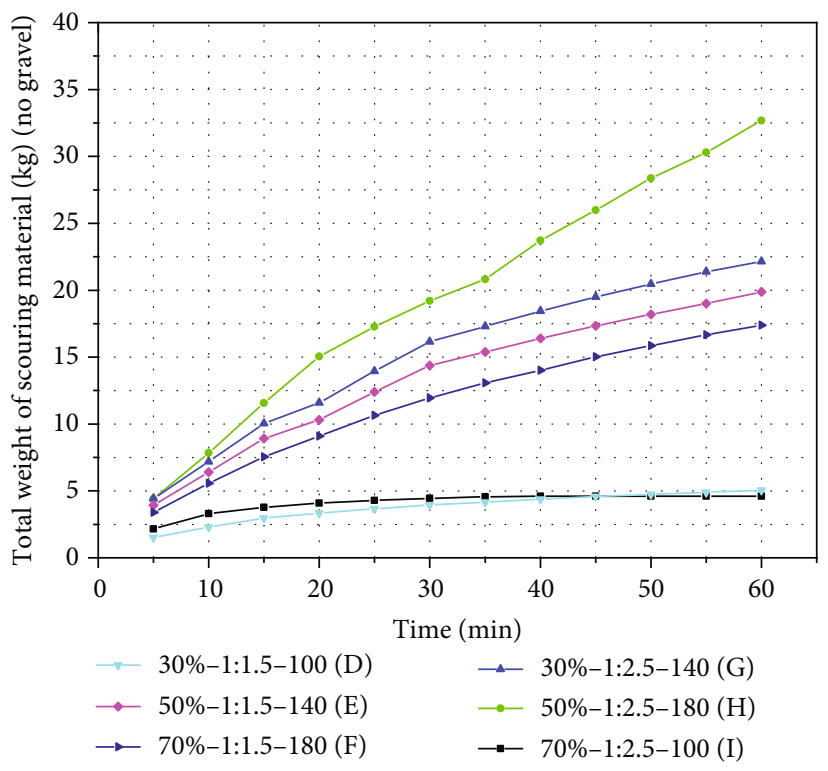

Figure 12: Time-history curve of the total mass of scoured material on gentle slopes.

ent conditions showed that when the slope was a gentle slope, it did not exhibit a large-scale landslide and instability, and the self-stability was good. Under these conditions, the total mass of the scouring material was inversely proportional to the gravel content and directly proportional to the rainfall intensity. This was because under gentle slope conditions, the slope was relatively stable under the given rainfall conditions, and there would be no large-scale landslides. The energy generated by the runoff was proportional to the intensity of the rainfall; however, the maximum energy at this time was not sufficient to wash away the gravel; it could only wash away the soil particles around the gravel, and the gravel collapsed into the pit under the action of gravity. The increase in the gravel content mainly hindered the runoff. Therefore, 


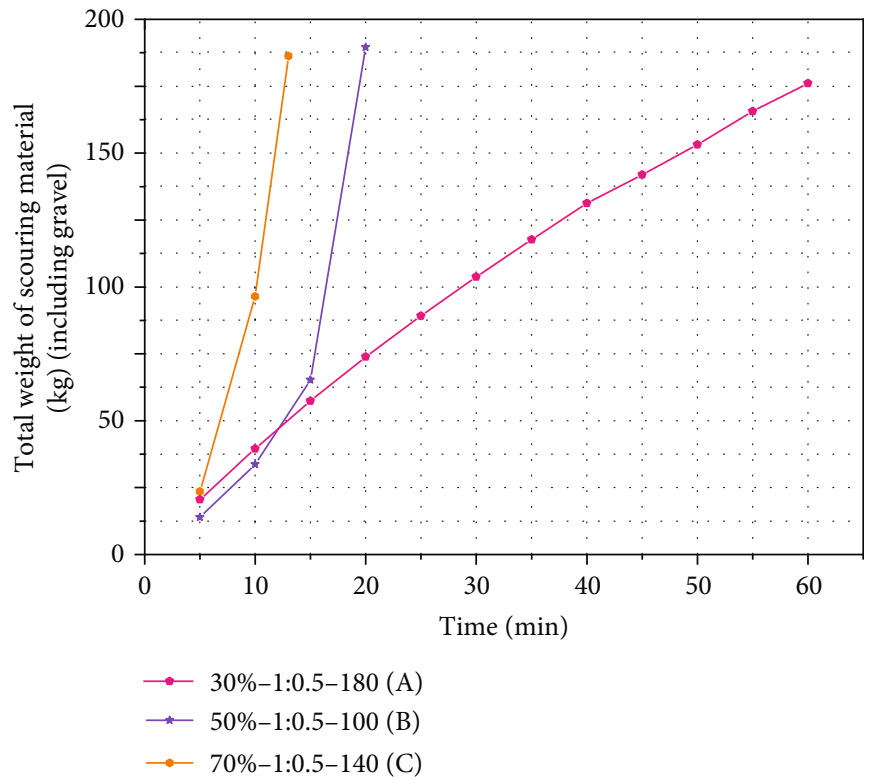

Figure 13: Time-history curve of the total mass of scoured material on steep slopes.

the total mass of the scouring material was affected by the two layers of gravel and rainfall intensity. The total mass of the scouring material decreased with an increase in the gravel content and increased with an increase in the rainfall intensity.

\subsection{Relationship between the Total Mass of Scoured Material} on Steep Slopes, Gravel Content, and Rainfall Intensity. As shown in Figure 13, when the slope is steep, test C had a large area of landslide and instability when the rainfall time was $13 \mathrm{~min}$, while sample B exhibited the same phenomena when the rainfall time was for $20 \mathrm{~min}$. We believe that the slope became unstable at this time, and the test was stopped. Under different rainfall conditions, all the steep slopes had a certain amount of landslide and instability, coupled with poor self-stability. The total mass of the scoured material increased with an increase in the rainfall intensity and gravel content. The reasons are as follows: (1) as the slope increased, the scouring force of the runoff along the slope increased; the scouring effect of the runoff increased; the antisliding force of the gravel on the slope decreased. In addition, when the content of gravel was high, the pores of the soil increased; the initial cracks increased in size; the clay could not completely wrap the gravel; the cohesive force of the clay gravel layer decreased; the erosion resistance decreased. Therefore, the clay gravel was more susceptible to erosion. (2) With an increase in the rainfall intensity, the scouring effect of the runoff was further strengthened and eddy currents with stronger denudation capability were easily formed around the gravel, and the scouring effect on the particles was enhanced. At the same time, the energy of the runoff was sufficient to wash away the gravel, and the slope was more prone to erosion.

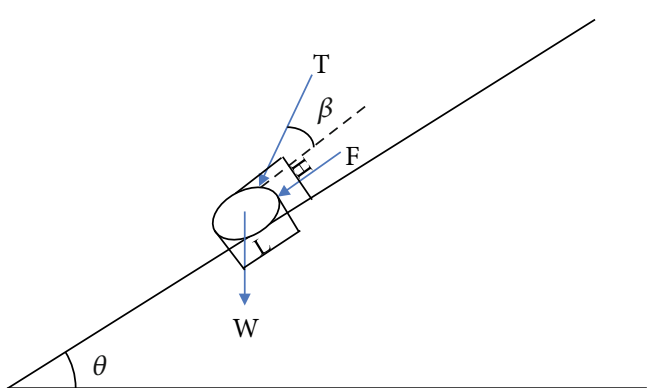

FIgURe 14: Presents a simplified diagram of the force on the gravel of the clay gravel slope.

5.3. Influencing Factors of Gravel Content in the Scoured Material. When the slope was gentle, there was no gravel in the scour from the clay gravel layer; however, when the slope was steep, the scour from the clay gravel layer contained gravel. Therefore, the key factor that decides whether gravel was contained in the scoured clay gravel layer was the slope ratio of the sloping surface. Based on Wang et al. [27], Figure 14 is a simplified diagram of the gravel stress on the clay gravel slope. The slope of the sloping surface is $\theta$; the cohesion of the clay gravel layer is $C$; the friction angle is $\varphi$; $T$ is the impact force of raindrops on the gravel; $F$ is the scour force of the runoff on the gravel; $W$ is the gravity of the gravel; the angle between $T$ and the slope direction is $\beta$. When rainfall on the slope surface formed a slope surface runoff, a water film was formed on the surface of the gravel, and the impact of raindrops on the gravel was very weak and could be ignored. After random statistics of 200 different elliptical gravels were considered, the short axis length $H$, long axis length $L=0.73: 1$, and the short axis length of the gravel in the width direction were almost equal to $H$. Therefore, the gravel was equivalent to a rectangular 
TABLE 4: Stability coefficient of gravel fall of clay gravel layer slope.

\begin{tabular}{lccc}
\hline $\begin{array}{l}\text { Test } \\
\text { number }\end{array}$ & $\begin{array}{c}\text { Saturated cohesion } \\
\text { of gravel layer }(\mathrm{kPa})\end{array}$ & $\begin{array}{c}\text { Saturated friction } \\
\text { angle of gravel layer } \\
\left({ }^{\circ}\right)\end{array}$ & $\begin{array}{c}\text { Stability } \\
\text { coefficient }\end{array}$ \\
\hline A & 15.8 & 19.3 & 0.829 \\
B & 16.4 & 18.6 & 0.850 \\
C & 13.6 & 17.3 & 0.717 \\
D & 15.8 & 19.3 & 1.513 \\
E & 16.4 & 18.6 & 1.541 \\
F & 13.6 & 17.3 & 1.313 \\
G & 15.8 & 19.3 & 2.316 \\
H & 16.4 & 18.6 & 2.356 \\
I & 13.6 & 17.3 & 2.012 \\
\hline
\end{tabular}

parallelepiped, with its length $(L)$, width $(D)$, and height $(H)$ equal to $1: 0.73: 0.73$. Supposing that the volume of gravel was $V$ and the area in contact with the sloping surface was $S$, the slip resistance of the gravel is

$$
N=W \cdot \cos \theta \bullet \tan \varphi+C \cdot S
$$

The sliding force is

$$
\begin{gathered}
N_{1}=W \bullet \sin \theta+F, \\
F=\gamma_{\text {water }} \bullet V \bullet \sin \theta .
\end{gathered}
$$

Therefore, the stability factor of gravel is

$$
F_{s}=\frac{N}{N_{1}} .
$$

According to the indoor triaxial test, the cohesion and internal friction angle of the saturated clay gravel layer under different rock content conditions are summarized in Table 4. The stability coefficients of nine groups of clay gravel layer slope gravel slipping were calculated from the previous test. As shown in Table 4, the stability factor was less than 1, indicating that the antisliding force of the gravel on the slope was less than the sliding force, the gravel was in an unstable state under the action of the runoff on the slope, and the gravel would slip. On the contrary, when the stability factor was greater than 1, the gravel would run off on the slope. In a stable state under these conditions, the gravel would not slip off. The calculated results were consistent with the experimental observations. It shows that whether the gravel falls off of the clay gravel slope mainly depends on the slope ratio, and the gravel content also had a certain influence.

\section{Conclusions}

When the slope was gentle, the failure of the sloping surface appeared as an erosion damage. The degree of damage at different positions of the sloping surface increased from the top of the surface to the bottom of the surface. The overall degree of erosion of the slope in test I was the smallest and had the greatest degree of overall erosion. When the slope was steep, it had a large area of collapse and instability. When the gravel content was $30 \%$, the slope was revealed as a gully failure. When the gravel contents were $50 \%$ and $70 \%$, the slope was revealed as a "layer-by-layer" sliding failure.

Under conditions of different gravel contents, slope ratios, and rainfall intensities, the runoff rate and infiltration rate of the clay gravel layer slope changed similarly. Taking 10 min of rainfall as the limit, the runoff on the slope was divided into a growth phase and a stable phase. The slope infiltration was divided into a descending phase and a stable phase. There were small-scale fluctuations in both the stable stages, which were mainly owing to the unstable development of the slope erosion, for example, the widening of rills, collapse of ditch walls, and blocking effect of gravel falling into the rills on the runoff. After $10 \mathrm{~min}$ of rainfall, the order of the degree of influence of each factor on the stable runoff rate was as follows: rainfall intensity>slope ratio>gravel content. The order of the degree of influence on the stable infiltration rate was slope ratio>rainfall intensity>gravel content. It is generally believed that the infiltration rate of a slope decreases with an increase in the slope ratio, and the test results in this study showed that the stable infiltration rate of the slope first decreased and then increased with an increase in the slope ratio, mainly because the slope was steep. The slope had a large area of collapse, which provided a passage for infiltration and increased the effective infiltration area of the slope.

When the rainfall intensity was constant, the most favourable combination of the gravel content and slope ratio for stable runoff of the slope was 30\%-1:1.5. Under these conditions, the slope was not conducive to the infiltration of rainwater, and the rainwater flowed along the sloping surface. The quality of the clay in the middle wrap was low; the slope damage was low; the slope stability was high. The combination of gravel content and slope ratio that was most conducive to a stable infiltration of the slope was 70\%-1:0.5. Under these conditions, the slope was most conducive to the infiltration of rainwater; the slope had a large area of collapse; the stability of the slope was the lowest.

When the slope was a gentle slope, the total mass of the scoured material was inversely proportional to the gravel content and proportional to the rainfall intensity. When the slope was steep, the total mass of the scoured material increased as the rainfall intensity and gravel content increased. At the same time, the key influencing factor that decided whether there was gravel in the scour was the slope ratio of the slope.

\section{Data Availability}

No data were used to support this study.

\section{Conflicts of Interest}

The authors declare no conflict of interest. 


\section{Acknowledgments}

This research was funded by the National Natural Science Foundation of China, grant number 41702337.

\section{References}

[1] J. De Vente and J. Poesen, "Predicting soil erosion and sediment yield at the basin scale: scale issues and semiquantitative models," Earth-Science Reviews, vol. 71, no. 12, pp. 95-125, 2005.

[2] S. Zhang, W. Qiao, Y. Wu, Z. Fan, and L. Zhang, "Experimental study on seepage characteristics of microfracture with different aperture," Scientific Reports, vol. 10, no. 1, p. 5452, 2020.

[3] R. B. Bryan and D. L. Rockwell, "Water table control on rill initiation and implications for erosional response," Geomorphology, vol. 23, no. 2-4, pp. 151-169, 1998.

[4] G. A. Mancilla, S. Chen, and D. K. McCool, "Rill density prediction and flow velocity distributions on agricultural areas in the Pacific northwest," Soil \& Tillage Research, vol. 84, no. 1, pp. 54-66, 2005.

[5] H. O. Shen, F.-l. Zheng, L. Wang, and L. L. Wen, "Effects of rainfall intensity and topography on rill development and rill characteristics on loessial hillslopes in China," Journal of Mountain Science, vol. 16, no. 10, pp. 2299-2307, 2019.

[6] L. Zhao, R. Hou, F. Wu, and S. Keesstra, "Effect of soil surface roughness on infiltration water, ponding and runoff on tilled soils under rainfall simulation experiments," Soil \& Tillage Research, vol. 179, no. 1, pp. 47-53, 2018.

[7] J. An, F. Zheng, J. Lu, and G. Li, "Investigating the role of raindrop impact on hydrodynamic mechanism of soil erosion under simulated rainfall conditions," Soil Science, vol. 177, no. 8, pp. 517-526, 2012.

[8] D. Torri, M. Sfalanga, and G. Chisci, "Threshold conditions for incipient rilling," Catena, vol. 8, pp. 97-105, 1987.

[9] G. Govers, "Relationship between discharge, velocity and flow area for rills eroding loose, nonlayered materials," Earth Surface Processes and Landforms, vol. 17, no. 5, pp. 515-528, 1992.

[10] M. A. Nearing, L. D. Norton, D. A. Bulgakov, G. A. Larionov, L. T. West, and K. M. Dontsova, "Hydraulics and erosion in eroding rills," Water Resources Research, vol. 33, no. 4, pp. 865-876, 1997.

[11] H. R. Liang, X. X. Yu, D. X. Fan, J. M. Sun, and Y. Chang, "Influence of gravel cover on sediment yield on slope surface," Science of Soil and Water Conservation, vol. 28, pp. 57-61, 2014.

[12] H. Wang, D. B. Lu, D. J. Huang, and C. J. Shan, "On the erosion characteristics of red soil slope with different gravel existence forms," Science of Soil and Water Conservation, vol. 17, no. 4, pp. 49-58, 2019.

[13] F. S. Jiang, Y.-h. Huang, M. K. Wang, J. S. Lin, G. Zhao, and H. L. Ge, "Effects of rainfall intensity and slope gradient on steep colluvial deposit erosion in southeast China," Soil Science Society of America Journal, vol. 78, no. 5, pp. 1741-1752, 2014.

[14] F. S. Jiang, Z. Zhan, J. Chen et al., "Rill erosion processes on a steep colluvial deposit slope under heavy rainfall in flume experiments with artificial rain," Catena, vol. 169, pp. 46-58, 2018.

[15] X. N. Liu, D. Fan, X. Yu, Z. Liu, and J. Sun, "Effects of simulated gravel on hydraulic characteristics of overland flow under varying flow discharges, slope gradients and gravel coverage degrees," Scientific Reports, vol. 9, no. 1, article 19781, 2019.

[16] C. Qin, F. Zheng, X. Xu, H. Wu, and H. Shen, "A laboratory study on rill network development and morphological characteristics on loessial hillslope," Journal of Soils and Sediments, vol. 18, no. 4, pp. 1679-1690, 2018.

[17] H. Rahardjo, T. Lee, E. Leong, and R. B. Rezaur, "Response of a residual soil slope to rainfall," Canadian Geotechnical Journal, vol. 42, no. 2, pp. 340-351, 2005.

[18] P. Tahmasebi and S. Kamrava, "A pore-scale mathematical modeling of fluid-particle interactions: thermo- hydromechanical coupling," International Journal of Greenhouse Gas Control, vol. 83, pp. 245-255, 2019.

[19] D. F. Cen, D. Huang, and F. Ren, "Shear deformation and strength of the interphase between the soil-rock mixture and the benched bedrock slope surface," Acta Geotechnica, vol. 12, no. 2, pp. 391-413, 2017.

[20] K. Huang, Z. J. Dai, F. Yu, J. W. Wang, and X. X. Shan, "In situ strength characteristics of clay gravel layer in Anqing formation considering water environment and external load," Rock and Soil Mechanics, vol. 2, pp. 1-9, 2020.

[21] E. Medley, "Orderly characterization of chaotic Franciscan Melanges,” Engineering Geology, vol. 19, no. 4, pp. 20-33, 2001.

[22] B. B. Mandelbrot, The Fractal Geometry of Nature New Work, WH freeman, New York, 1983.

[23] Y. Wang and X. Li, "Study of mesoscopic fractal feature and mechanical properties for rock and soil aggregates samples," Journal of Rock Mechanics and Engineering, vol. 34, pp. 3397-3407, 2015.

[24] K. T. Fang and C. X. Ma, Orthogonal and Uniform Test Design, Science Press, Beijing, China, 2001.

[25] Z. Zhou, H. Yang, X. Wang, and B. Liu, "Model development and experimental verification for permeability coefficient of soil-rock mixture," International Journal of Geomechanics, vol. 17, no. 4, pp. 1-10, 2017.

[26] F. S. Jiang, P. J. Chen, Y. H. Huang et al., "Experimental study on erosion hydrodynamic characteristics of concentrated flow on soil-rock mixed colluvial deposit slope," Science of Soil and Water Conservation, vol. 31, pp. 8-14,99, 2017.

[27] X. Wang, W. K. Ni, H. S. Liu, P. Wu, and Z. Yuan, "Simulation experiment on loess slope rainfall erosion mechanism," Chinese Journal of Geological Hazards and Prevention, vol. 26, pp. 41-45, 2015. 